\title{
Desterrados del parnaso (el Verso "POPUlaR" RIOPLATENSE: VOCES/ HOJAS/ MENSAJES)
}

OUt OF THE PARNASSUS (THE "POPULAR" POETRY OF ARGENTINA AND URUGUAY: VOICES/ FLIERS/ MESSAGES)

Pablo Rocca

Universidad de la República

Uruguay

\begin{abstract}
Resumen
Las diferentes formas de consagración se enfrentan con serias dificultades ante textos de autores anónimos o sin trayectoria alguna, que vienen de la oralidad y pretenden llegar a cierto tipo de público por vías editoriales precarias. Este artículo indaga dos modulaciones de este problema. En primer lugar, el del payador, que hacia 1885, en su fase consagratoria en Argentina y Uruguay, buscó salir de la oralidad y alcanzar el estatus de poeta que le negaron quienes practicaban este discurso desde la escritura. En segundo término, se observan dos tipos de cultores de la modesta hoja volante o el periodismo de ocasión que quiso llegar a un público de pocas letras para politizarlo. En esa frontera porosa se exploran algunos problemas que atraviesan el siempre esquivo concepto de lo "popular" (que, por lo mismo, se cita siempre entre comillas), entre la oralidad y la escritura.
\end{abstract}

Palabras-clave: Poesía popular; Performance oral; escritura.

\section{Resumo}

As diferentes formas de consagração tem sérias dificuldades com textos de autores anônimos ou sem trajetória, textos que provém da oralidade e tentam alcançar certo tipo de público por precárias vias editoriais. Este artigo indaga diferentes variantes do problema. Em primeiro lugar, o do payador, isto é o intérprete que por volta de 1885 , em sua fase de consagração na Argentina e no Uruguai, procurou fugir da oralidade para alcançar o status do poeta, o mesmo que lhe era negado pelos praticantes desse discurso desde a escrita. No segundo lugar, é possível achar dois tipos de praticantes da modesta folha ou o jornalismo ocasional que tento chegar a um público escassamente letrado de poucas letras com a

\section{Abstract}

When discussing different ways of achieving literary success, anomymous texts and obscure authors who come from orality and try to reach their audiences through precarious publishing houses face serious difficulties. Firstly, we have payadores, who around 1885 , as they were entering their heyday in Argentina and Uruguay, tried to get out of orality and reach the status of poet denied to them from those who were established as practitioners of the poetic discourse in written form. Secondly, we have two different kinds of practitioners of the humble flier or occasional journalism. These media tried to reach a scarcely literatized audience in order to gain political influence over it. Moving on this porous border explore 
finalidade de politizá-lo. Nessa fronteira se pesquisam alguns problemas que atingem o sempre esquivo conceito do "popular" (que, pelo mesmo, se coloca neste artigo sempre entre aspas), entre a oralidade e a escrita.

Palavras-chave: Poesia popular; Performance oral; escrita. some topics between orality and literacy are explored, topics crossed by the elusive concept of the "popular" (always enclosed in quotation marks here for that reason). Keywords: Popular Poetry; Oral performance; Literature.

En 1885 se imprimió en Montevideo un pequeño libro de setenta y cuatro páginas: Colección de canciones del payador oriental Juan de Nava. Un siglo antes, en 1773, el viajero cuzqueño Concolorcorvo, vio y escuchó a unos hombres rústicos que entonaban con una "guitarrita [...] varias coplas, que estropean, y muchas que sacan de su cabeza, que regularmente ruedan sobre sus amores" (CONCOLORCORVO, 1963: 33). Desde entonces el circuito payadoresco creció en las pulperías o en los fogones de las estancias para afirmarse en pueblos y ciudades del Río de la Plata. En 1885 estaba preparado para dar el salto del canto al impreso, por derecho propio y no por las sucesivas capturas de su voz y sus motivos por la retórica culta y, sobre todo, política que encontró en la gauchesca la mejor aunque no la exclusiva manifestación de este acto de apropiación. En esa nueva etapa prevalecían, como en el mundo de la interpretación, los nombres del oriental Juan de Nava y el argentino Gabino Ezeiza (ROCCA, 2013).

Habitual cultor de la performance oral, Juan de Nava cumplía ese deseo con su primer opus, presidido en su portada por un retrato suyo dibujado de cuerpo entero. El volumen incluía décimas, octavas y redondillas. Invariables octosílabos equilibran las composiciones serias con las humorísticas. Al primer registro le corresponde el uso de un castellano respetuoso de la norma castellana; el segundo, más numeroso, se acerca al habla rioplatense aunque tomando una prudente distancia de la variante gauchesca que había alcanzado su consagración una década y poco atrás con el Martín Fierro. Sin embargo, de Nava recobra y radicaliza una apuesta de la gauchesca cuando parodia el lenguaje de los gallegos y, en especial, los italianos -numerosísimos entonces y por muchos otras décadas en las ciudades del Plata-a los que, además, incorpora como personajes de la payada de contrapunto para hacerlos funcionar de modo verosímil en su relato. Esa apuesta novedosa se cumple pri- 
mero en el "Canto de contrapunto. Entre el Payador Oriental y el Italiano José Richetti, el cual tuvo lugar en una estancia del Departamento de Minas (República Oriental)" (DE NAVA, 1885: 39-44).

El poeta-payador inventa ese intercambio versificado al borde mismo de la fértil primavera de la "literatura Giacumina" fugaz variante dialectal inspirada en un personaje que, hasta donde se ha investigado, brotó en las dos márgenes del Plata en 1886 (apud ANÓNIMO, 2011). Ya en ese mismo ańo 86 en el "Canto de contra punto [sic] que tuvo el cantor Oriental con el Italiano Yacumin Ravanetti, en la Estancia llamada de Bador en la Costa de los Palmares", el yo-narrador-autor-personaje se encuentra ante parejo desafiante. Lánguido, desconfiado, trata de eludirlo, pero su rosto le resulta familiar al otro, y la sospecha de estar ante un profesional en el género se valida cuando una vieja acerca el reciente libro de versos que trae su retrato:

Luego lansó en derredor,

Una mirada segura,

Y sus ojos se clavaron,

Sobre mi caricatura:

Parecía estaba en duda,

Sobre si me conocía,

O si abría visto algún dia,

Estampada mi figura.

Conforme me miró un rato,

Me dijo muy placentero,

Lo conozco forastero

$\mathrm{O}$ yo he visto su retrato.

Y yo con grande recato,

Me estaba haciendo el chiquito,

Cuando una vieja un librito,

Trajo de adentro de un cuarto.

Conocí por la carátula,

Que eran mis composiciones,

Y que me habían descubierto,

En aquellos rededores.

Luego en manifestaciones,

Se vinieron los paisanos, Hasta que el diablo Italiano,

Me dedicó estos renglones.,

Aura que le he descobrido,

$\mathrm{Nu}$ se vaya hacer rugar,

Perque tiene que cantar,

Aquí un mumento conmigo;

Quiero pruebarle mi amigo, 
Adrento dista reunión,

A ver si é cume me dicen,

Cuerte in impruvisación.

(DE NAVA, 1886: 17).

El librito es el que se había publicado un año atrás con una colorida carátula a dos tintas: celestes franjas horizontales que simbolizan la bandera uruguaya y, en el centro, la estampa del autor con un traje colorado, encerrado en un óvalo. La imagen presenta a un hombre de mediana edad, grueso, de cuidado cabello renegrido y levemente ondulado; pulsa una guitarra española y viste un ceñido trajecito de verano. En su rostro rebosa un bigote generoso y una expresión severa pero cordial. Suficiente información gráfica en ese mundo casi sin imágenes para ser recordado. Al margen de la parodia del italiano, ese es el pacto ficcional que de Nava quiere establecer entre el verso que se improvisa y el que se imprime para la memoria y el archivo de los que poseen un breve pero firme capital simbólico. Si en la segunda parte del Martín Fierro (1875) el reconocimiento de quien mató al hermano del payador negro se procesa en el curso del diálogo versificado, en el texto de Juan de Nava la imagen precede al duelo de voces y por eso otorga una configuración dramática sin riesgos aparentes para un desenlace violento entre los contendores.

Al pasar, de Nava distingue a quien canta en la lengua nacional frente a quien la mancilla con un lenguaje mostrenco, que rebaja aun más el artificio de la escritura. Paradójicamente, esto no hace más que mostrar que estamos ante un juego de convenciones y artificios verbales posibles. Salvo los escasos versos del Martín Fierro y algunos aislados ejemplos de la gauchesca anterior al poema de José Hernández en que algunos italianismos van salpicando el cuerpo central del texto, hasta donde sabemos nunca antes la poesía rioplatense había representado el enfrentamiento entre un payador criollo y un gringo. En ese duelo verbal se escenifican por lo menos cuatro niveles lingüísticos: el español estándar; la variante gauchesca que -como sabemos hoyes más una construcción literaria que un espejo del habla de la pradera rioplatense; el italiano más o menos canónico y una variante hibrida entre esta lengua y el castellano. Juan de Nava aprovecha esta tensión que produce una riqueza creativa notables y la expone con humor y con una dosis importante de xenofobia, seguramente celebrada por todos los sectores sociales criollos, $\tan$ reactivos contra los gringos: ${ }^{1}$

José

Aura si que mambrumao

Amigu si aduvinára,

\footnotetext{
${ }^{1}$ Sobre la reacción antigringa en Argentina, véase HALPERIN DONGHI, 1993 y DEVOTO, 2004; sobre el mismo tema en Uruguay: ODDONE, 1968 y RODRÍGUEZ VILLAMIL, 1968.
} 
¿Cume sabe que he cumido

Ina yunta é botifara?

Payador

Veo que Ud. no comprende

El lenguaje castellano;

No ha dejado el italiano

Para ponerse á cantar

Y si así vá á continuar

Mejor será que dejémos

Y un ratito, pues, le oirémos

Aquí solo improvisar

(DE NAVA, 1885: 40-41).

Un nuevo orden social y nuevos discursos se están imponiendo en ese "mundo del ochenta" (JITRIK, 1998). Los poetas que vienen de la entraña de la comunidad oral han comprendido que para sobrevivir necesitan el medio impreso. Este empieza a triunfar a partir de precarias mediaciones materiales (folletos, hojas) consumidas por los neoalfabetos, pero con la ansiada compensación de lograr consumos mayores, y por la paralela legitimación que la poesía de matriz oral hacen los dotores en sus artículos, sus libros y sus historias anecdóticas.

Oír y leer: pocas veces más evidente esta alianza entre el oído y el ojo que entenderá la canción y el poema como formas diferentes pero coincidentes en un punto, como "objetos sonoros" antes que cualquier otra cosa (VILARIÑO, 1989: 1). Como en los modestos versos del gran payador-poeta José Betinotti (1878-1915), publicados por primera vez en 2012: En mi conciencia discreta/ afirmo, y luego respondo./que el payador en su fondo/tiene algo de poeta [...] ("Un pensamiento", BETINOTTI, 2012: 27)

II

Payadores y gauchescos actúan en el teatro social según su oportunidad y su contexto. La vulgarización de las ideas a través del canto no fue exclusivo usufructo de las divisas tradicionales de una u otra orilla del Plata, en tiempos en que ya los estados nacionales se han afirmado. Seguramente percibiendo su eficacia comunicativa con las mayorías, y recogiendo una noción romántica de lo "popular", ya a comienzos del siglo XX algunos anarquistas - no, por cierto, los escritores más notorios de este grupo - se sumaron a este discurso (PRIETO, 1988; REY DE GUIDO \& GUIDO, 1989). Ciertas producciones se mimetizaron con el gauchesco en un intento de apropiación de la ideología de los bandos conservadores. Una de ellas se difundió por 1920 
en las prensas de La Batalla a través de un modesto folletito (Carta gaucha escrita pa los gauchos, de Juan Crusao, seud. de Luis Woollands), en el que se anuncia una tirada de veinte mil ejemplares de la obra (ROCCA, 2009: 20).

Varias décadas más tarde la fuerza del sistema poético de raíz criolla era tal que el Partido Comunista uruguayo, necesitando crecer entre los sectores rurales que le daban la espalda, la fomentó entre sus adeptos como vehículo de propaganda. El diario Justicia -órgano oficial del Partido- convocó a sus lectores a que mandaran composiciones en estilo gauchesco que definieron como "payadas", cuando en rigor eran textos rigurosamente escritos. Bajo el colgado "Otra cosa es con guitarra" y con el título tomado de dos versos del Martín Fierro ("Los hermanos sean unidos/ porque esa es la ley primera"), el $4 \mathrm{de}$ agosto de 1953 se publicaron quince piezas a página entera formato sábana. Los textos, firmados o con seudónimo, pertenecen a autores al margen del canon literario de la época en un claro gesto de incorporación de la voz del sujeto de abajo, al que se le asigna ese lugar que se identifica con lo criollo. En esas muchas coplas se aclama al Partido, a su Secretario General (Eugenio Gómez), a la causa proletaria, a su diario local, a la Unión Soviética, y simultáneamente se ataca a los sectores tradicionales y a los Estados Unidos. No se esquiva el culto a la personalidad, como en "El más sabio conductor", de Mario Bentancour:

¡Qué camino recorrido lleva Gómez, camaradas!

Triple fecha homenajeada por el Puerto y el Partido Certero el rumbo ha seguido -iqué gran cabeza, la pucha!"en el foco de la lucha" siempre a la masa prendido, es el Padre del Partido: como a un padre se le escucha. (BENTANCOUR, 4/VIII/1953: s/p)

En otras ocasiones, se asocia la idea de la revolución contemporánea a la gesta revolucionaria originaria que en la Banda Oriental había comandado desde 1811 a 1820 el General José Artigas. Eso ocurre, por ejemplo, en un texto que Ademar Gómez remite desde la pequeña ciudad de Treinta y Tres, en el que hay eco del poema "Orejano" (de Tacuruses, 1935), de su coterráneo Serafín J. García, por más que en este priva un aliento anárquico que, en el del presunto discípulo, se encuadra en un movimiento emancipador y en un jefe. Traslaticiamente los dos se pueden asimilar al Partido Comunista y su Secretario general: 
De un rincón a otro rincón

de nuestra tierra querida

recorre otra vez erguida

la figura magistral

del más querido oriental

nuestro padre José Artigas.

[...]

No se detenga a escuchar

lo que le dice el dotor:

sólo ha de sentir dolor

el que su voz les escuche

pues ellos llenan el buche

y son como sanguijuelas,

no perdonan ni a su abuela

si de los pesos se trata,

y al pobre por su trabajo

no le dan ni pa'alpargata.

(GÓMEZ, 4/VIII/1953: s/p)

La única mujer que interviene ese día, quien oculta su nombre y apellido pero no el de su marido, manda desde Salto un poema con versos mal medidos y ritmos desacompasados, que poco se acercan al registro oral. Con todo, su fervor por el Secretario General del Partido lleva a los redactores de Justicia a incluirlos entre el conjunto neocriollo ya que en ellos, ahora sin embozo, Artigas se reencarna en Eugenio Gómez:

Gracias a tus luchas, Gómez,

esperanza del proletariado,

que en las luchas difíciles

firmes siempre están a tu lado.

La clase trabajadora

siguiéndote Gómez, va

a ti, oh glorioso jefe

estrella de amor y paz.

$[\ldots]$

Oh, descendiente de Artigas,

con los mismos ideales

corre la sangre en tus venas

por tus pobres orientales

(M. B. P. DE ROCCA, 4/VIII/1953: s/p)

Hay que notar que la primera gauchesca fue cautelosa en la creación de héroes criollos. Exaltar al héroe de este medio rural supondría el riesgo de redimir al gaucho proponiendo al protocaudillo - que el discurso letrado estilizó y convirtió en héroe liberal justamente desde 1885 - en el mejor de 
los gauchos. De hecho, ningún texto de Bartolomé Hidalgo, el fundador del género, aúpa a esta categoría a José Artigas o a sus comandantes y pocos son los que hacen lo mismo después de la independencia con Fructuoso Rivera, Manuel Oribe o Juan Manuel de Rosas, salvo durante la prolongada Guerra Grande (1843-1851) del lado oriental del Plata que coincide con la dictadura rosista de la otra margen. Si bien el apóstrofe del jefe enemigo y sus servidores presionó al género, política que Hilario Ascasubi llevó a sus extremos de eficacia comunicativa y refinamiento retórico, otros poemas del género llegarán a encarnar en algunos jefes guerreros las cualidades de la civilización. Hasta en los gringos como Giuseppe Garibaldi o el comandante de la escuadra inglesa que apoya a Montevideo contra los ejércitos de Oribe y Rosas. Eso se verifica en el diálogo entre Vicente y Juan de Dios, de autor anónimo, publicado en un folleto en 1843 :

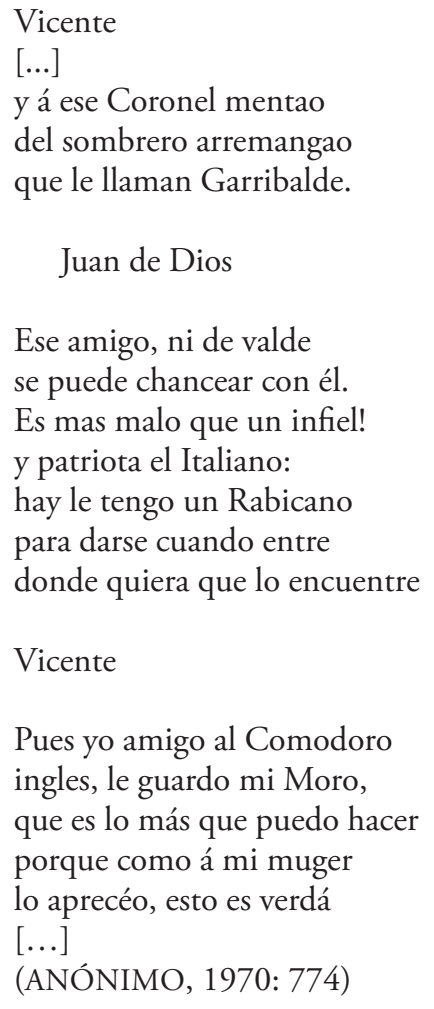

Simultáneamente, la poesía académica crea sus héroes civiles y militares escogiéndolos entre los primeros defensores de la independencia contra los españoles y portugueses, o en los presidentes constitucionales, algunos de ellos caudillos montoneros (como Rivera) que se ponen el traje de ciudadanos, con el que se los prefiere recordar como lo testimonian decenas de poemas de 
Juan Crisóstomo Lafinur, Juan Cruz Varela, Acuña de Figueroa, y muchos otros que se encuentran en La lira argentina, compilada por Ramón Díaz en 1824, en el Parnaso Oriental, de Luciano Lira (1835-1837) o en la póstuma e inconclusa Colección de poetas del Río de la Plata (2011 [circa 1845]). ${ }^{2}$

En cualquier caso, para la gauchesca, siempre mejor la ley que el ídolo, que no podría ser sino el padre de los gauchos. Cuando una personalidad representa el derecho y el orden, según la variante ideológica que sea, podrá recuperar el centro del canto patrio.

III

Desde la segunda mitad del siglo XIX, una vez que empieza a construirse el canon nacional a un lado y otro del Plata, una vez que la gauchesca salta de la hoja al periódico y de este al folleto y luego al libro, se difunde en hojas sueltas la poesía de creadores menores o la de quienes se arrojan a la circunstancial celebración o su reverso. Obra de poetas que no pudieron editar un folleto - no se hable de un libro bien encuadernado -, porque les falta dinero, porque no consiguen el apoyo de un impresor ni, menos, de la crítica o quizá porque la meta codiciada de la mayoría está en el rápido efecto poético-político (o, mejor, político-poético) sobre un receptor apartado de los medios de difusión más orgánicos. Los expulsados del Parnaso, con su magro patrimonio, sólo pudieron comunicarse con la frágil hojita. Todavía hoy persisten aunque el papel parece batirse en retirada, aunque las formas de reproducción se abarataron y multiplicaron.

Sobre la constante difusión de literatura por medios de mínimo costo, algo significativo para la sensibilidad de tantos, no existe en América Latina estudio alguno ni hasta hace poco los archivos solían ocuparse de estas figuras y de sus materiales fuera de todo catálogo. Las bibliotecas los han expulsado y es difícil que alguien confíe en su valor. Cuesta medir su recepción y hay que tener cuidado en identificar de manera total la penuria del medio con la pobreza radical del creador. Esta es una vía posible, pero no la única, ya que ha gravitado la urgencia por trasmitir mensajes políticos utilizando las fórmulas métricas y sonoras que facilitan su memorización poniendo el acento en lo informativo más que en lo propiamente estético. Como han planteado Miguel A. García y Gloria B. Chicote en su estudio de la enorme colección de folletos criollos reunida en La Plata por Roberto Lehmann-Nitsche -un verdadero precursor-hay un "carácter desechable" en esta literatura "ya que fue

\footnotetext{
${ }^{2}$ Ejemplo extremo de esta variación temática de la poesía neoclásica, de la que los Parnasos están llenas, es la exaltación de Rivera en versos escritos en latín y traducidos al castellano, publicados en $E l$ Nacional en noviembre de 1838. Debemos el descubrimiento y su copia a la minuciosa investigación de Victoria Herrera (Cf. INTROINI; HERRERA \& MOREIRA, 2012: 82-85).
} 
escrita para consumo inmediato a través de la memorización y no para ser resguardada en los estantes de un archivo o biblioteca" (GARCÍA \& CHICOTE, 2008: 25). En efecto, pocos se interesaron en este material al que juzgaron estéticamente inválido desde una mirada artepurista, un inconexo conjunto textual que no deja de asociar limitación material con impotencia creativa. Gracias a los eruditos y a los historiadores algo pudo salvarse. En una serie de notas sobre grandes bibliotecas personales, Ángel Rama llegó a la casa del historiador uruguayo Juan E. Pivel Devoto, quien confesó que desde su infancia, en 1916 (es decir a los seis años de edad) comenzó a coleccionar hojas sueltas de cualquier género discursivo, desde panfletos a poemas. Para 1961 había acumulado "millares de piezas: 'La hoja suelta, como el folleto, tuvo siempre un carácter más ágil, más polémico que el libro: era la proclama, el manifiesto, la alarma, lo que ahora es el boletin de la radio" (RAMA, 1961).

Cuando la hoja sirve como vehículo para un poema es algo más que información, es el arte del pobre o el del que pretende llegar a las mayorías que están muy alejados del libro. Entre las hojas sueltas o pliegos simples que conozco saltan toda clase de temas. Hay cándidos versos dedicados a la madre, la naturaleza o las zozobras interiores en el amplio friso de posibilidades que ofrecen las batallas de amor. Un ilustrativo ejemplo de otro tema que, hasta hace pocos años, seguía vivo y llamaba la atención de los escuchas son los versos de "El Gauchito del Talú", quien imprimía sus composiciones burlescas de asunto futbolístico y estilo semigauchesco y uno o más vendedores recitaban algunos fragmentos en las tribunas del Estadio Centenario de Montevideo. Después de haber atraído a su público con suficientes muestras sobre episodios del momento, el vendedor ofrecía en venta el conjunto en grandes hojas de formato tabloide que se plegaban. Allá a principios de la década del setenta recuerdo haber escuchado con asombro la atención general, hasta las risas cómplices, y recuerdo que el negocio no era del todo desdeñable. Hoy, por lo menos, sobrevive bajo este mismo seudónimo un hábil versificador que cierra un programa futbolístico que se emite en la emisora montevideana Oriental. Otra muestra de las mutaciones continuas del género en el que la décima y la octava continúan en pie.

Un alto porcentaje de los versos volanderos se dedica a lo político, en general bajo la ponderación o el maltrato de una personalidad pública, en homenaje a un caído o en el calor de una disputa civil o militar. Estas piezas pueden ser estimadas como heterodoxas legatarias de la gauchesca. De mi pequeña colección particular, compuesta por unas tres decenas de piezas, formada por azar (parte considerable de las hojas encontradas dentro de libros o revistas que compré usados) elijo cuatro casos de distintos puntos del Río de la Plata entre 1886 y 1969. Dos son del siglo XIX, dos de la cen- 
turia siguiente, lo cual habla de la relativa pervivencia de lenguajes y la firme continuidad de medios difusores durante el reino de la imprenta. Esta actividad repetida no se transforma en una producción seriada en esta zona americana, probablemente porque la escolarización había crecido incorporando una gran masa de lectores de periódicos, folletos y aun libros. Ni por asomo estas hojas se acercan al tipo de producción de la literatura de cordel, propia de comunidades apartadas de los planes educativos dirigistas y por eso tan explosiva en el nordeste brasileño desde fines del siglo XIX. ${ }^{3}$

Sospecho que los impresos rioplatenses de los que me ocuparé se brindaron gratuitamente o por una contribución voluntaria en diferentes espacios públicos, según la época, la circunstancia y el sector social al que pertenezca el autor. Todos están firmados, algunos con seudónimo. Ninguno tiene la más mínima entrada en diccionario o historia literaria. De ahí que, pese a algunos esfuerzos, no poseo el menor dato biográfico de los autores ni otras referencias bibliográficas útiles para situar los textos elegidos. Mejor así: esta incuria nos coloca frente al texto casi desnudo. Casi, porque la referencia política en un lenguaje que se entrega al sentido más visible justifica la existencia del mensaje sirviéndole de significante fuerte.

En estos poemas aislados se advierte la apología del soldado o el escarnio del tirano por una voz exterior o interna, rural o urbana, pero que siempre quiere establecer un puente con el auditor-lector en un régimen elocutivo que impone una versión de la realidad sin amortiguaciones. Cuando no se opta por un discurso inflamado y exterior a la situación narrada se retoma el viejo artificio de la voz del gaucho-soldado o la del soldado-civilizado.

"A José Visillac", de R. de Iturriaga y López, la hoja más antigua de todas las seleccionadas, fue compuesta en "La Plata, Mayo 13 de 1886" y se ordena en cuatro octavillas endecasílabas. Esta apología del jefe criollo uruguayo perseguido por el general Máximo Santos se vierte en un lenguaje engolado, ahíto de adjetivos, como los que presiden la última estrofa: "La suerte te fué adversa: en la batallal una mortal herida recibistel $Y$, ensangrentado, exánime caistel De tu brioso y magnifico corcel' (DE ITURRIAGA y LÓPEZ, 1886). A contrapelo, el gobernante militar encarna todos los males públicos y en su fuerza radica su debilidad futura: "iPobre ambicioso! ;sabe que los pueblos/ No perdonan jamás a su verdugo?' La pompa neoclásica más apta para estas operaciones, a despecho del tema y el sujeto que lo instiga, sobrepuja al estilo gauchesco. Este amaga recobrarse de tal convalecencia, pero no lo hace, en las cuatro décimas alineadas en "Al heróico General Lamas. Vencedor de 'Tres

\footnotetext{
${ }^{3}$ Sobre un fenómeno hoy vigente, aunque oficializado, y que fue atendido por la crítica brasileńa o sobre la cultura de Brasil, consúltese CURRAN, 2003. La página web de la Academia Brasileira de Literatura de Cordel es <http://www.ablc.com.br/>.
} 
Árboles'”, de Eugenio G. López, que debió publicarse en ocasión de la visita de Diego Lamas a Buenos Aires, aunque en realidad este llegó al grado de coronel en la revolución saravista de 1897. Poco después del final de la guerra, a fines de octubre de ese año, Lamas fue homenajeado en Buenos Aires por un numeroso grupo de civiles así como de oficiales del Ejército argentino en el que había servido en los largos años anteriores a la campaña del 97 (MENA SEGARRA, II, 1996). No es la única pieza de esta clase que lo alaba, ${ }^{4}$ y seguro que salió antes de la muerte accidental de Lamas, ocurrida el 20 de mayo de 1898, seis años antes del próximo levantamiento de Aparicio Saravia. Dos datos sugieren que la hoja se imprimió en Argentina y en la especial ocasión del homenaje de octubre de 1897: "El ejército Argentino/ Te saluda placenterol Y te ensalza...", dice al comienzo de la Décima 2a y tres franjas celestes atraviesan el papel, dos en los extremos y otra en el centro, todas en diagonal, representando la unión de los colores de las banderas argentina y uruguaya. Si el templado texto nacionalista se inicia de modo mayestático con "Gloria y prez del nuevo mundo/ Tu serás eternamentel Caudillo audaz y valiente", aunque no hay término que provenga de la oralidad, la invectiva del enemigo lo acerca a un estilo que impuso la gauchesca en estas tierras: "Que aplaste el reptil inmundo/ Que odiamos de corazon/ Y un grito de maldicion/ Repercuta por el mundo?' (Décima 4a).

Podría postularse, con razón, que los dos textos referidos del siglo XIX están más adentro del universo de la escritura que en el de la oralidad aunque, como sabemos, esta no puede definirse sino a través de la primera, así como lo "popular" no puede ser delineado sin su contrario, esto es: lo selecto, lo elitista. Estrategias diversas de la pedagogía: los poetas del XIX, de seguro origen burgués u oligárquico, quieren "civilizar" al público de escasas letras al tiempo que concitar la adhesión a sus causas; en las dos hojas del siglo XX el platillo parece inclinarse para el campo oral, ya sea por la posible pertenencia a sectores sociales pequeńo burgueses de sus practicantes, ya porque el discurso impregnado por la oralidad se ha canonizado.

El 25 de marzo de 1964 alguien que se identifica con pelos y señales -domicilio incluido- y se presenta como "Versificador Minuano", continúa haciendo una poesía política sometida a esta lógica del elogio y su reverso

\footnotetext{
${ }^{4}$ Otra hoja, de autor anónimo, reproducida por C. Enrique Mena Segarra, es una sucesión de décimas en las que se derraman elogios por este orden a los jefes blancos de 1897: Aparicio Saravia, Lamas, Juan Francisco Mena y José González. El texto de un creador ostensiblemente culto es anterior a la muerte del coronel Lamas, aunque no vacila en considerarlo inmortal antes de tiempo: "Quede su nombre estampadol como heroico en nuestra historial y en el campo de la glorial donde la espada ha empuñadol nazca la flor del sagradol lema de la libertad, / que el pais con ansiedadl de su fragancia hoy espera" (MENA SEGARRA, I, 1996: 113). Mena Segarra no conoció o, por lo menos, no mencionó la pieza que comento en el texto central. Otras formas del canto a Lamas, asociado esta vez a Saravia y a Eduardo Acevedo Díaz fueron estudiadas en ROCCA, 2014.
} 
como canto fúnebre, esta vez ante la muerte de Benito Nardone. Son "Décimas póstumas [sic] dedicadas con todo cariño y recuerdo, y en homenaje al gran lider ruralista y más grande demócrata del Uruguay y de América Latina del siglo veinte" (DEL PUERTO, 1964). Una pequeña y desvaída foto del conductor de la conservadora Liga Federal de Acción Ruralista y ex Consejero Nacional de Gobierno, acompaña estas diez imperfectas décimas. Con la seriedad propia del poeta de pocas letras (BORGES, 1979: 10), este versificador inhábil en el manejo de la lengua lucha con vocablos prestigiados por la lírica culta, condimentados con americanismos y el código distintivo del decir panfletario:

Fué firme cual atalaya

Fué fuerte cual coronilla

Hoy es estrella que brilla

En nuestra patria uruguaya

Porque hombres de su taya

No nacen todos los días

"Él", tuvo la valentía

De enfrentar al enemigo

Que con sucios adjetivos

Cobardes lo combatían

(Décima 5a)

Seis décimas integran también la composición "Como en la Dictadura de Máximo Santos”, difundida en una pequeña hoja fechada en diciembre de 1969 e impresa probablemente en Melo (departamento de Cerro Largo), donde la hallé dentro de un libro viejo en una biblioteca particular a comienzos de la década del noventa. En ellas se retoma las características de la poesía gauchesca inicial: violenta denuncia política de hechos presentes, registro de matriz oral, vocablos corrientes en el género ("aparcero", "patacones", "pucha"). Sólo en el título se evoca al autoritarismo santista, ya que el texto suspende los términos de comparación, con lo que señala ese momento histórico como una suerte de grado cero de la tiranía y la corrupción, posibilidad que había anunciado el autor de "A José Visillac" en 1886. El hablante del poema de 1969, travestido con el seudónimo "El Manco Apolinario", se presenta como partidario del senador Amiscar (errata por Amílcar) Vasconcellos, enfurecido por lo que considera una traición a los ideales batllistas - es decir, la original formulación socialdemócrata uruguaya - por parte del Presidente Jorge Pacheco Areco y su equipo gobernante (1967-1971). Desde esa posición protesta contra

Desfalcos al por mayor,

Lo de La Pluna y la Aduana,

revaluos de mañana

y otro en la tarde. Un primor 
Pucha si el Tayador

me da entrada al redondel,

fullerando, tras de el,

haría un fino trabajo,

metiéndole el mesmo tajo

que los “Tupa” en San Rafael.

(Décima 2a)

[...]

Yo no veo

la manera,

que arreglen ese escenario,

donde el pueblo en su calvario,

ve un Parlamento entregado.

Y a Pacheco acorralado,

con el fondo monetario.

(Fragmento de la Décima 6a)

(EL MANCO APOLINARIO, 1969)5

Versos escritos para destinatarios no siempre refinados (o principalmente no refinados) que si acaso los leen o, tal vez, si un poco compulsivamente los escuchan, aseguran la comunicación con el oyente-lector por la rapidez con que es posible descodificar su mensaje. Priva en ellos el sello individual, que desde luego no es lo mismo que decir originalidad ni - en la intrincada red teórica que se enfrenta a lo popular - tampoco entra en los dominios de lo tradicional ni de lo folklórico, para acudir a la precisa justificación que Margit Frenk hace del título general de sus ensayos sobre Lyra mínima (FRENK, 2006: 12). Herederos de la tensión entre oralidad y escritura que proviene de la gauchesca, confiados en la transparencia de la palabra para la difusión del mensaje, estos poetas marginales de diferentes épocas y siempre desterrados de cualquier Parnaso, al que por entrar darían cualquier cosa, se ubican en una frontera conflictiva. Desde allí incomodan algo a quienes lograron su lugar en la historia literaria y mucho más a quienes nos encargamos de construir taxonomías y, no hay otro remedio, valoraciones.

\footnotetext{
${ }^{5}$ Parece tentador comparar las diferencias de lenguaje, a pesar de la común idea crítica y carnavalizante, de estas décimas con el soneto "El guantudo", que Roberto Ibáñez publicó por ese entonces en Marcha, cuya primera estrofa dice: "Vuelve a tu bolsa, vuelve al pugilato/ Presidente casual y policíaco./ Sobrio jamón, trasero candidato/ Ungido por un sincope cardíaco". El texto, según declaraciones de la Prof. Norah Giraldi-Dei Cas en la Facultad de Humanidades y Ciencias de la Educación en 2001, circuló también en la época en una pequeña hoja volante que, para una exposición de la mencionada investigadora, hizo copia de la que reproduzco el fragmento antecitado.
} 


\section{Referencias bibliográficas}

ANÓNIMO (1824). La Lira Argentina. Buenos Aires: Biblioteca de Mayo, 1960: 4.692-5.219. Tomo VI: "Literatura". (Reproducción facsimilar de la edición de 1824, B. A.).

ANÓNIMO (1970). "Diálogo que tuvieron el día 11 del corriente los paisanos Juan de Dios Oliva, Martin Zamora y Vicente Morales que llegó al campamento del General Rivera”, Revista Histórica, Montevideo, T. XLI, n. 121-123, 2a época: 761-774.

ANÓNIMO (2011). Literatura popular inmigratoria. Buenos Aires: Biblioteca Nacional. (Contiene diversos textos de la llamada "Literatura Giacumina", 1886 y ss).

BENTANCOUR, Mario. “El más sabio conductor”, Justicia, Montevideo, n. 5.444, 2a Sección, 4 ago. 1953: s/p.

BETINOTTI, José. Versos. Buenos Aires: Leviatán, 2012.

BORGES, Jorge Luis. El Martín Fierro. Buenos Aires, Emecé, 1979.

CONCOLORCORVO. El Lazarillo de ciegos caminantes: desde Buenos Aires hasta Lima, 1773. Montevideo: Ministerio de Instrucción Pública y Previsión Social, 1963.

CURRAN, Mark. História do Brasil em cordel. São Paulo: Edusp, 2003.

DE ITURRIAGA \& LÓPEZ, R. “A José Visillac”. Poema en hoja volante, 185 por 275 mm., datada en "La Plata, Mayo 13 de 1886". (Copia en archivo particular del autor de este trabajo).

DE NAVA, Juan. Colección de canciones del payador oriental Juan de Nava. Montevideo: Juan B. Vaillant; Imp. Tipografía de la Guía General de Comercio, 1885.

- El cantor oriental: colección de canciones del payador Juan de Nava. Segunda serie. Montevideo: Imp. Escuela de Artes y Oficios, 1886.

DEL PUERTO, Pedro E. "El cóndor plegó sus alas". Poema en hoja volante, 200 por $285 \mathrm{~mm}$. Al pie de la composición se lee: Autor: Pedro E. del Puerto. Versificador Minuano. Rincón de Carrasco. Ruta 101 Km. 24.300, Dpto. Canelones. Prohibida la reproducción sin la autorización del autor. Marzo 25/1964. (Copia en archivo particular del autor de este trabajo).

DEVOTO, Fernando. Historia de la inmigración en la Argentina. Buenos Aires: Editorial Sudamericana, 2004.

EL MANCO APOLINARIO. "Como en la Dictadura de Máximo Santos”. Poema en hoja volante, 140 por $205 \mathrm{~mm}$., Dic/1969. (Copia en archivo particular del autor de este trabajo).

FRENK, Margit. Poesía popular hispánica: 44 estudios. México: FCE, 2006.

GARCÍA, Miguel A. \& CHICOTE, Gloria B. Voces de tinta: estudio preliminar y antología comentada de Folklore argentino (1905) de Robert LehmannNitsche. La Plata: Ed. de la Universidad de La Plata, 2008. (acompańa CD con grabaciones de canciones populares registradas a comienzos del siglo XX).

GÓMEZ, Ademar. "Hay rumores de alborada", Justicia, Montevideo, n. 5.444, 2a Sección, 4 ago. 1953: s/p. 
JITRIK, Noé. El mundo del ochenta. 2. ed. Buenos Aires: Editores de América Latina, 1998.

HALPERIN DONGHI, Tulio. “¿Para qué la inmigración?: ideología y política inmigratoria en la Argentina (1810-1914)". In: . El espejo de la historia. Buenos Aires: Editorial Sudamericana, 1993: 228-229.

HIDALGO, Bartolomé. Obra completa. Montevideo: Biblioteca Artigas, 1986. (Colección de Clásicos Uruguayos).

INTROINI, Juan; HERRERA, Victoria \& MOREIRA, L. Augusto. Viejas liras y nuevos vates: literatura uruguaya y tradición clásica. Montevideo: Universidad de la República, 2012.

LAMAS, Andrés; GUTIÉRREZ, Juan María; INDARTE, José Rivera \& VILARDEBÓ, Teodoro M. Colección de poetas del Río de la Plata. Prólogo y notas de Pablo Rocca. Trascripción paleográfica de Valentina Lorenzelli Montevideo: Biblioteca Artigas, 2011. (Clásicos Uruguayos).

LIRA, Luciano (Org.). El Parnaso Oriental o Guirnalda poética de la República uruguaya. Prólogo y fichas de Juan E. Pivel Devoto. Montevideo: Biblioteca Artigas, 1981. (Colección de Clásicos Uruguayos - Reimpresión facsimilar de los tres tomos editados entre 1835 y 1837, los dos primeros en Buenos Aires y el último en Montevideo).

LÓPEZ, Eugenio G. (circa 1897). "Al heróico General Lamas. Vencedor de 'Tres Árboles'”. Poema en hoja volante, 190 por $270 \mathrm{~mm}$. (Copia en archivo particular del autor de este trabajo).

DE ROCCA, M. B. P. “Cantos a Eugenio Gómez”, Justicia, Montevideo, n. 5.444, 2a Sección, 4 ago. 1953: s/p.

MENA SEGARRA, C. Enrique. "Los poemas populares". In: Las banderas de Aparicio y otras historias. Montevideo: Cal y Canto, 1996, v. I: 106-117.

" "Diego Lamas en Buenos Aires (1897)". In: . Las banderas de Aparicio y otras historias. Montevideo: Cal y Canto, 1996, v. II: 118-126.

ODDONE, Juan A. Los gringos. Montevideo: Editores Reunidos, 1968. (Enciclopedia Uruguaya, n. 26).

PRIETO, Adolfo. El discurso criollista en la formación de la literatura argentina. Buenos Aires: Sudamericana, 1988.

RAMA, Ángel. "La biblioteca de un historiador (Juan E. Pivel Devoto)", Marcha, Montevideo, n. 1.501, 24 mar. 1961: 23.

REY DE GUIDO, Clara \& GUIDO, Walter (Selección, prólogo y notas). Cancionero rioplatense (1880-1925). Caracas: Biblioteca Ayacucho, 1989.

ROCCA, Pablo. "Acerca de las representaciones de lo rural". In: HIDALGO, Bartolomé et. al. Tradiciones Rurales. Montevideo: Comisión del Patrimonio Cultural de la Nación; Ministerio de Educación y Cultura, 2009: 14-22.

"Los poetas-payadores de la modernización (Un desafío para la historia de la lírica rioplatense)", Miscelanea, v. 14, jul./dez. 2013: 9-30. Disponível em: <http://goo.gl/BGSWdd>. Acesso em: 20 nov. 2015.

"Dar lugar al desengańo. Acevedo Díaz, Sánchez y el caudillismo". In: MIRZA, Roger \& DUBATTI, Jorge (Ed.). Florencio Sánchez contemporáneo: 
perspectivas rioplatenses. Montevideo: Universidad de la República; MEC, 2014: 169-210.

RODRÍGUEZ VILLAMIL, Silvia. Las mentalidades dominantes en Montevideo (18501900): la mentalidad criolla tradicional. Montevideo: Ediciones de la Banda Oriental, 1968, v. I.

VILARIÑO, Idea. La masa sonora del poema: sus organizaciones vocálicas Indagaciones en algunos poemas de Rubén Darío. Montevideo: Arca, 1989.

Pablo Rocca é Doutor em Letras (USP), Professor Titular de Literatura Uruguaia na Universidad de la República (Montevidéu), Diretor e fundador do Arquivo literário da mencionada Universidade desde 1999 e Pesquisador, nível II, da Agencia Nacional de Investigación e Innovación (Ministério da Educação e a Cultura, Uruguay) a partir de 2010. Publicou: 35 años en Marcha (1991; 3. ed., 2015); Horacio Quiroga, el escritor y el mito, 1996 (reed. 2007); Historia de la literatura uruguaya contemporánea (1996-1997, em co-direção com Heber Raviolo); Poesía y política en el siglo XIX (2003); Angel Rama, Emir Rodríguez Monegal y el Brasil: Dos caras de un proyecto latinoamericano (2006); Revistas culturales del Río de la Plata (1942-1964) (2009). Traduziu e organizou vários livros de autores brasileiros, entre eles de Machado de Assis, Lima Barreto, Murilo Rubiāo, João do Rio, Sérgio Faraco, Tabajara Ruas, a maior parte publicados em Montevidéu. E-mail: pabloroccapesce@gmail.com 